\title{
A HELLP syndrome complicates a gestational trophoblastic neoplasia in a perimenopausal woman: a case report
}

\author{
Guillaume Vogin ${ }^{1 *}$ (D), François Golfier ${ }^{2,3}$, Touria Hajri ${ }^{3}$, Agnès Leroux ${ }^{4}$ and Béatrice Weber ${ }^{5,1}$
}

\begin{abstract}
Background: HELLP syndrome is a combination of symptoms described as hemolysis, elevated liver enzymes and low platelets, that complicates $0.01-0.6 \%$ of pregnancies. HELLP syndrome has been scarcely reported associated with partial moles, another rare complication of pregnancy. This manuscript describes the only reported case of HELLP syndrome associated with a complete invasive hydatiform mole.

Case presentation: We report a perimenopausal patient in prolonged remission from an uncommon high-risk invasive complete mole. The diagnosis was set in a context of early onset preeclampsia and HELLP syndrome. The development of life-threatening complications required primary hysterectomy. Postoperative hCG quickly returned to normal with EMA/CO multi-agent chemotherapy.

Conclusion: Our patient is in prolonged remission from a complete mole complicated with EOP and HELLP syndrome. This exceptional case of complicated gestational trophoblastic neoplasia reflects a very rare condition in which several risk factors for placental ischemia are associated. Emergency hysterectomy should be considered as salvage initial treatment in such life-threatening situations.
\end{abstract}

Keywords: Preeclampsia, HELLP syndrome, Gestational trophoblastic neoplasia, Perimenopause

\section{Background}

HELLP, a syndrome characterized by hemolysis, elevated liver enzyme levels and a low platelet count, is a very rare and severe obstetric complication that usually presents in the third trimester of pregnancy [1].

In perimenopausal women, spontaneous pregnancy is rare and associated with an increased incidence of maternal complications such as pregnancy-induced hypertension and the related complications: preeclampsia and HELLP syndrome [2].

Specifically in this age group in parallel, the risk of gestational trophoblastic disease (GTD) has been reported as high as 1 in 8 pregnancies over the age of 50 - with a higher potential for malignant transformation [3-6]. GTD not only refers to premalignant entities such as complete and partial hydatiform moles (HM) but also to malignant diseases - termed gestational trophoblastic

\footnotetext{
* Correspondence: g.vogin@nancy.unicancer.fr

${ }^{1}$ Department of Radiation Oncology, Institut de Cancérologie de Lorraine,

Avenue de Bourgogne, 54500 Vandoeuvre Les Nancy, France

Full list of author information is available at the end of the article
}

neoplasia (GTN) - such as invasive mole, choriocarcinoma, placental site and epithelioid trophoblastic tumours. Reference treatment of HM in reproductive age women is uterine evacuation while chemotherapy is indicated to treat FIGO low- or high-risk GTN [6]. In perimenopausal women, a primary hysterectomy can be recommended either as a method for uterine evacuation of HM or as a primary treatment of non-metastatic GTN with or without severe bleeding $[5,7]$.

\section{Case presentation}

A 52- year old perimenopausal caucasian woman, gravida 3 para 3, with a 10-week long vaginal bleeding, bloating, fatigue, weight gain $(>7 \mathrm{~kg})$, and hypogastric mass was admitted to the local emergency room for an epigastric pain and a mild dyspnea. She also observed breast tenderness for the last 3 months. Her personal history included: appendectomy, amiodarone-induced hypothyroidism, chronic atrial fibrillation and breast abscess but not hypertension. Her last delivery was 23 years ago and she discontinued oral contraceptive pill at least 18 months 
back. She then observed hot flashes and menstrual irregularity with longer menstrual cycles and her last menses occurred 4 months ago.

A computed tomography (CT) scan of the chest, abdomen and pelvis showed a uterine enlargement $(15 \times 12 \mathrm{~cm}$ axial) with a heterogeneous hypodense endometrium punctuated with nodular areas enhanced by iodinated contrast (Fig. 1a \& b). Neither fetus nor adnexal mass was detected. Diffuse bilateral pulmonary nodules were observed (Fig. 1c). While her serum hCG level was $0.96 \times 10^{6} \mathrm{IU} / \mathrm{L}$, an endometrial trans-cervical biopsy showed two non-malignant chorionic villi.

When she was referred to the regional cancer center ten days later, she was further diagnosed with the following signs of early onset preeclampsia (EOP): new onset of severe hypertension $(170 / 100 \mathrm{mmHg})$, proteinuria, oliguria, headache, hyper reflexivity in lower limbs and growing epigastric pain radiating to both hypochondria. While her fundal height was measured to be $18 \mathrm{~cm}$, her laboratory tests including TBC, kidney and liver function were initially normal except a serum hCG test rising to $1.266 \times 10^{6} \mathrm{IU} / \mathrm{L}$. Blood pressure and diuresis were stabilized after a parenteral treatment of severe hypertension and pain. Her biological results, however, rapidly deteriorated with hemolytic anemia (hemoglobin $97 \mathrm{~g} / \mathrm{L}$, haptoglobin $<0.06 \mathrm{~g} / \mathrm{L})$, thrombocytopenia $(75 \mathrm{G} / \mathrm{L})$, and elevated liver enzymes (ALT $120 \mathrm{IU} / \mathrm{L}$, AST $252 \mathrm{IU} / \mathrm{L})$. Additionally, she developed severe proteinuria $(1.85 \mathrm{~g} / 24 \mathrm{~h})$. Together, she presented a complete form of HELLP syndrome. The patient was transferred to the intensive care unit and a salvage total abdominal hysterectomy with bilateral salpingo-oophorectomy was immediately decided in accordance with the French Trophoblastic Disease Reference Centre advice. Gross examination of the specimen showed an enlarged and tensed uterine body $(22 \times 20 \times 10 \mathrm{~cm}$, Fig. 2a) whose longitudinal incision released macroscopic vesicles without any identifiable fetus (Fig. 2b). Histological examination further revealed a complete and invasive hydatidiform mole (Fig. 2 c \& d). Histology was reviewed within the French network of trophoblastic disease referent pathologists.

One week after hysterectomy, her biological results markedly improved (hemoglobin $105 \mathrm{~g} / \mathrm{L}$, haptoglobin $2.7 \mathrm{~g} / \mathrm{L}$, platelets $311 \mathrm{G} / \mathrm{L}$, ALT $24 \mathrm{IU} / \mathrm{L}$, AST $23 \mathrm{IU} / \mathrm{L}$ and hCG $31.240 \times 10^{3} \mathrm{IU} / \mathrm{L}$.

Thoraco-abdomino-pelvic CT scan, liver MRI, brain CT and 18 F-FDG PET/CT detected diffuse metastases limited to the lungs (visible on chest $\mathrm{CT}$ scan but not by chest-X-ray). She was thus considered to develop a postmolar high-risk GTN with a FIGO stage/score of III:7 [8]. Therefore, an EMA-CO multi-agent chemotherapy was initiated at day 20 post-operative, as the patient left the intensive care unit [9]. She was subsequently registered in the national database with her informed signed consent [10]. Complete remission of GTN was ascertained by the rapid hCG regression within 10 weeks (Fig. 3). She was administered five EMA/CO cycles with two more consolidation courses after normalization of serum hCG levels that were periodically followed up to 24 months [11]. A complete response was observed on

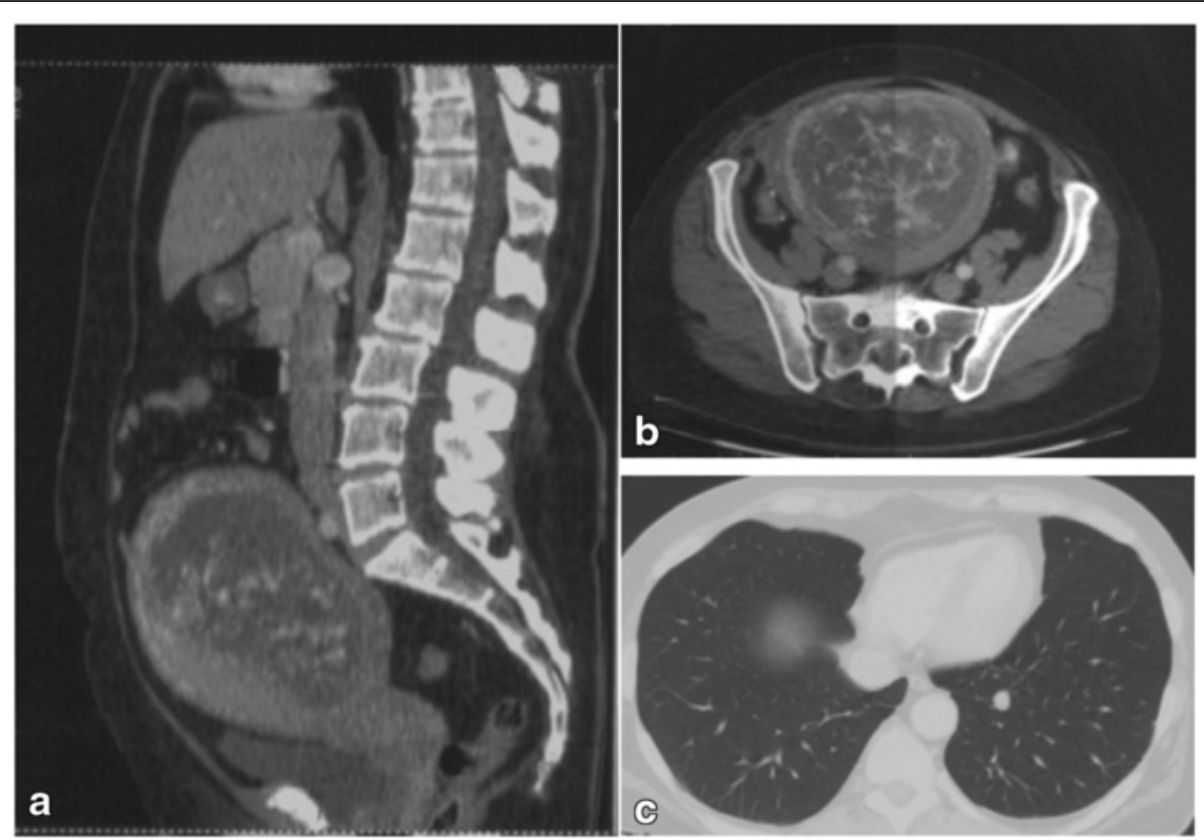

Fig. 1 Abdominopelvic contrast-enhanced CT scans showing an enlarged uterus with focal areas of hypoattenuation; a mid sagittal plane; b transverse plan. c Axial chest $C T$ scan (lung window) showing at least one left pulmonary metastase 


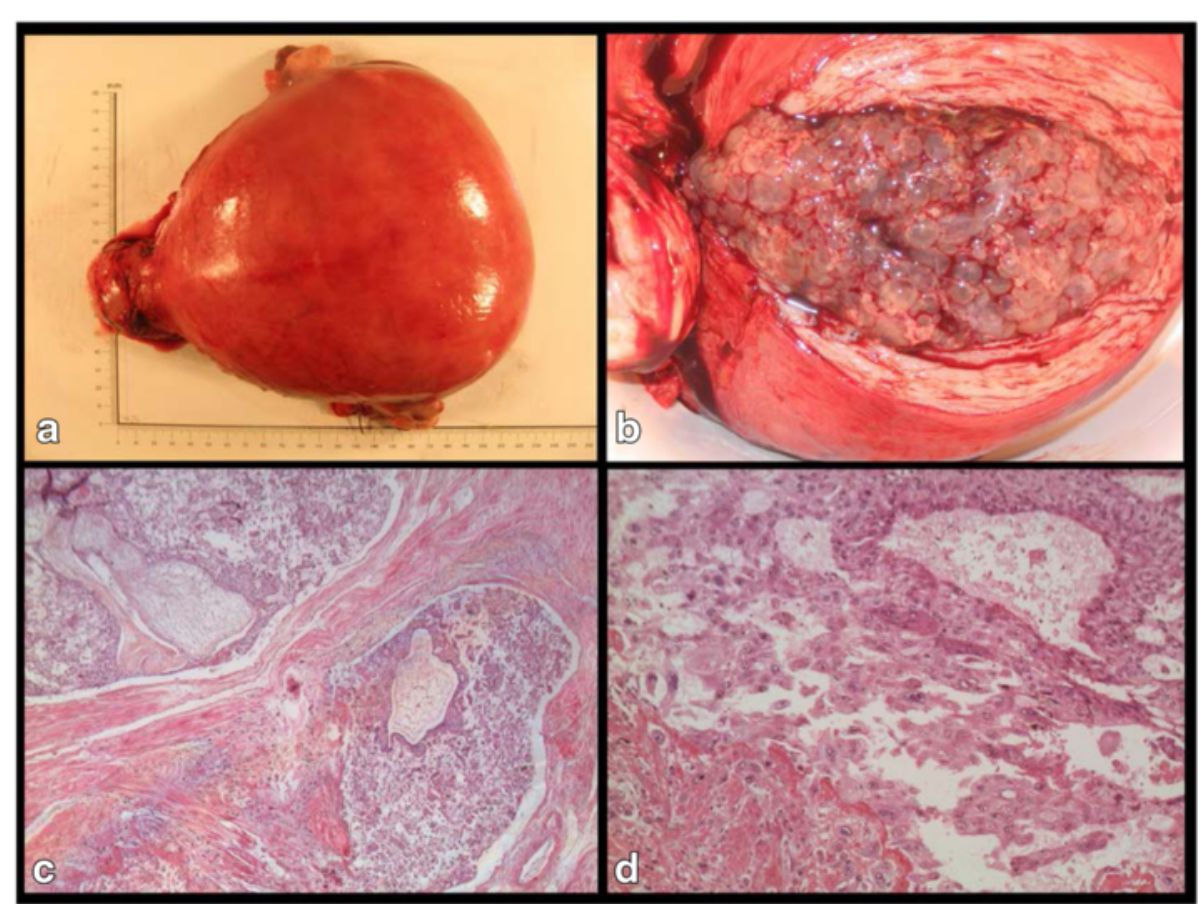

Fig. 2 a Photograph of the specimen with scale $(\mathrm{cm})$; b Photograph of the specimen with longitudinal incision exposing vesicles; $\mathbf{c}$ Low magnification micrograph of the invasive complete hydatiform mole component (hematoxylin and eosin): two enlarged chorionic villi associated with a trophoblastic proliferation invading the vessels and the muscular wall of the uterus (bottom left); $\mathbf{d}$ high magnification micrograph of a suspected choriocarcinomatous component (hematoxylin and eosin): large syncitiotrophoblasts associated with a proliferation of atypical intermediate cytotrophoblasts

the thoracic CT four months after diagnosis. The patient is disease-free for ten years.

\section{Discussion}

Patients in their sixth decade are not expected to be spontaneously pregnant, and a physician may not even think of checking hCG level when confronted with abnormal vaginal bleeding. Moreover low levels of hCG production in the perimenopausal and postmenopausal state is a normal physiologic phenomenon [12]. Therefore, the diagnosis of pregnancy and, moreover, GTD may be difficult.

In the particular case of our patient, we had to face an unusual clinical presentation. While the usual presenting symptoms of perimenopausal GTD are vaginal bleeding, stigmata of pregnancy with nausea or vomiting $[5,13]$, our patient presented with early onset preeclampsia (EOP), a rare condition that develops during the second

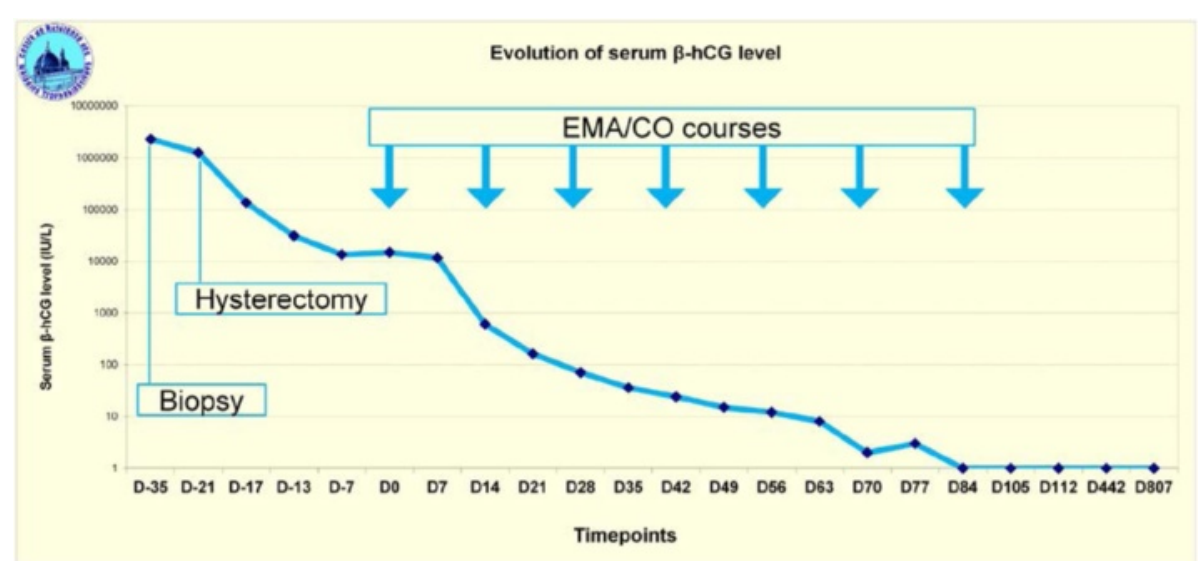

Fig. 3 Response to treatment measured by hCG tumour marker concentration in blood 
trimester of gestation and can complicate GTD, especially in older reproductive age women [14]. EOP is associated with a high incidence of HELLP syndrome and a 20-fold increase in maternal mortality $[15,16]$. EOP is particularly difficult to diagnose when preexisting disease such as hypertension is present, especially in peri/postmenopausal women. Other less common causes of severe hypertension, including thyrotoxicosis, pheochromocytoma and recreational drug use, should be considered in the differential diagnosis. EOP and some glomerulopathies - possibly related to hypertension - may have similar clinical and laboratory findings. Conversely preeclampsia itself increases the risk of kidney disease later in life. The main differential diagnoses of HELLP include thrombotic microangiopathies (thrombotic thrombocytopaenic purpura and haemolytic uraemic syndrome (HUS) and acute fatty liver of pregnancy.

Another atypical characteristics of the disease reported here is the absence of described association between HELLP syndrome and complete hydatidiform moles, whatever the age of the patients. Only HELLP syndromes with partial moles have been scarcely reported [17-19].

\section{Conclusion}

Our patient is in prolonged remission from a complete invasive mole complicated with EOP and HELLP syndrome. The development of such a life-threatening complication can require emergency primary hysterectomy, which can be recommended as the first curative approach of GTN when childbearing considerations have been fulfilled. Relationship of this exceptional HELLP syndrome in a GTN should be further investigated.

\section{Abbreviations \\ $(\beta-) h C G$, ( $\beta-)$ human chorionic gonadotropin; ALT, alanine aminotransferase; AST, alanine aminotransferase; EMA/CO, etoposide, methotrexate, and dactinomycin/cyclophosphamide and vincristine; EOP, early onset preeclampsia; GTD, gestational trophoblastic disease; GTN, gestational trophoblastic neoplasia;} HELLP, Hemolysis - Elevated Liver enzymes - Low Platelet count

\section{Acknowledgements}

Dhvanit I Shah (writing assistance), Perrine Granger, Fanny Pelluard and the French network of referent pathologists in trophoblastic disease (pathology), François Galon (surgery), Frederique Besozzi (artwork).

\section{Funding}

No funding was required for this study.

\section{Availability of data and materials}

Materials described in the manuscript will be freely available to any scientist wishing to use them for non-commercial purposes, without breaching participant confidentiality.

\section{Authors' contributions}

GV drafted the manuscript and reported the initial observation of the patient; FG coordinated the national review and helped to draft the manuscript; TH helped to retrieve the patient's data from the national database and coordinated the pathological review; AL performed the histological analysis of the specimen and animated the pathological discussion; BW managed the patient and helped to draft the manuscript. All authors read and approved the final manuscript.

\section{Competing interests}

The authors declare that they have no competing interests.

\section{Consent for publication}

Written informed consent was obtained from the patient for publication of this case report and any accompanying images. A copy of the written consent is available for review.

\section{Ethics approval and consent to participate - required}

The scientific committee of the Institut de Cancérologie de Lorraine approved the present study. In accordance with French regulations and due to the observational nature of this single patient retrospective study, no formal ethics approval is required (Law No. 2004-806 of 9 August 2004 amending Law No. 88-1138 of 20 December 1988 modified called "Huriet-Sérusclat law" on the protection of persons participating in biomedical research. Circular No DGS/SD1C/2005/123 of 7 March 2005).

\section{Sources of support}

None.

\section{Previous or duplicate publication}

None.

\section{Author details}

'Department of Radiation Oncology, Institut de Cancérologie de Lorraine, Avenue de Bourgogne, 54500 Vandoeuvre Les Nancy, France. ²Department of Obstetrics and Gynaecology, Lyon Sud University Hospital, Lyon, France. ${ }^{3}$ French Trophoblastic Disease Reference Centre, Lyon Sud University Hospital, Lyon, France. ${ }^{4}$ Department of Pathology, Institut de Cancérologie de Lorraine, Vandoeuvre les Nancy, France. ${ }^{5}$ Department of Oncology, Institut de Cancérologie de Lorraine, Vandoeuvre les Nancy, France.

Received: 21 January 2016 Accepted: 28 July 2016

Published online: 02 August 2016

\section{References}

1. Joshi D, James A, Quaglia A, Westbrook RH, Heneghan MA. Liver disease in pregnancy. Lancet. 2010;375(9714):594-605.

2. Berkowitz GS, Skovron ML, Lapinski RH, Berkowitz RL. Delayed childbearing and the outcome of pregnancy. N Engl J Med. 1990;322(10):659-64.

3. Savage PM, Sita-Lumsden A, Dickson S, lyer R, Everard J, Coleman R, et al. The relationship of maternal age to molar pregnancy incidence, risks for chemotherapy and subsequent pregnancy outcome. J Obstet Gynaecol. 2013:33(4):406-11.

4. Tsuji K, Yagi S, Nakano R. Increased risk of malignant transformation of hydatidiform moles in older gravidas: a cytogenetic study. Obstet Gynecol. 1981;58(3):351-5.

5. Elias KM, Goldstein DP, Berkowitz RS. Complete hydatidiform mole in women older than age 50. J Reprod Med. 2010;55(5-6):208-12.

6. Berkowitz RS, Goldstein DP. Current management of gestational trophoblastic diseases. Gynecol Oncol. 2009;112(3):654-62.

7. Hammond CB, Weed Jr JC, Currie JL. The role of operation in the current therapy of gestational trophoblastic disease. Am J Obstet Gynecol. 1980;136(7):844-58.

8. FIGO Oncology Committee. FIGO staging for gestational trophoblastic neoplasia 2000. Int J Gynaecol Obstet. 2002;77(3):285-7.

9. Newlands ES, Bagshawe KD, Begent RH, Rustin GJ, Holden L, Dent J. Developments in chemotherapy for medium- and high-risk patients with gestational trophoblastic tumours (1979-1984). Br J Obstet Gynaecol. 1986;93(1):63-9.

10. Golfier F, Raudrant D, Frappart L, Mathian B, Guastalla JP, Trillet-Lenoir V, et al. First epidemiological data from the French Trophoblastic Disease Reference Center. Am J Obstet Gynecol. 2007;196(2):172.e1-5.

11. Bower M, Newlands ES, Holden L, Short D, Brock C, Rustin GJ, et al. EMA/CO for high-risk gestational trophoblastic tumors: results from a cohort of 272 patients. J Clin Oncol. 1997;15(7):2636-43.

12. Cole LA, Sasaki Y, Muller CY. Normal production of human chorionic gonadotropin in menopause. N Engl J Med. 2007;356(11):1184-6.

13. Mangili G, Giorgione V, Gentile C, Bergamini A, Pella F, Almirante G, et al. Hydatidiform mole: age-related clinical presentation and high rate of severe complications in older women. Acta Obstet Gynecol Scand. 2014;93(5):503-7. 
14. Sibai BM. Imitators of severe preeclampsia. Obstet Gynecol. 2007;109(4):956-66.

15. MacKay AP, Berg CJ, Atrash HK. Pregnancy-related mortality from preeclampsia and eclampsia. Obstet Gynecol. 2001;97(4):533-8.

16. Varkonyi T, Nagy B, Fule T, Tarca AL, Karaszi K, Schonleber J, et al. Microarray profiling reveals that placental transcriptomes of early-onset HELLP syndrome and preeclampsia are similar. Placenta. 2011;32(Suppl):S21-9.

17. Falkert A, Yildiz A, Seelbach-Goebel B. Partial mole with fetal triploidy as a cause for imminent HELLP-syndrome at 16 weeks of gestation. Arch Gynecol Obstet. 2009;279(3):423-5.

18. Sherer DM, Dalloul M, Stimphil R, Hellmann M, Khoury-Collado F, Osho J, et al. Acute onset of severe hemolysis, elevated liver enzymes, and low platelet count syndrome in a patient with a partial hydatidiform mole at 17 weeks gestation. Am J Perinatol. 2006;23(3):163-6.

19. Stefos T, Plachouras N, Mari G, Cosmi E, Lolis D. A case of partial mole and atypical type I triploidy associated with severe HELLP syndrome at 18 weeks' gestation. Ultrasound Obstet Gynecol. 2002;20(4):403-4.

Submit your next manuscript to BioMed Central and we will help you at every step:

- We accept pre-submission inquiries

- Our selector tool helps you to find the most relevant journal

- We provide round the clock customer support

- Convenient online submission

- Thorough peer review

- Inclusion in PubMed and all major indexing services

- Maximum visibility for your research

Submit your manuscript at www.biomedcentral.com/submit
Biomed Central 